\title{
Co-supplying the National Grid: An Assessment of Private Off-grid Electricity Generation in Juba-South Sudan
}

\author{
Ladu David Morris Lemi*, Michael Carnegie La Belle \\ Department of Environmental Sciences and Policy, Central European University, Budapest, Hungary \\ Email address: \\ ladulemison@gmail.com (L. D. M. Lemi) \\ ${ }^{*}$ Corresponding author \\ To cite this article: \\ Ladu David Morris Lemi, Michael Carnegie La Belle. Co-supplying the National Grid: An Assessment of Private Off-grid Electricity \\ Generation in Juba-South Sudan. American Journal of Electrical Power and Energy Systems. Vol. 9, No. 3, 2020, pp. 47-59. \\ doi: 10.11648/j.epes.20200903.12
}

Received: July 2, 2020; Accepted: August 8, 2020; Published: August 19, 2020

\begin{abstract}
Despite the global campaign for energy transition towards renewable sources, South Sudan's electricity generation is exclusively diesel-based with an installed capacity of 12MW in Juba against 154MW demand. Persistent power outages have led to a rise in off-grid electricity self-generation using diesel generators. This study explored the available electricity generation options in Juba, quantified the off-grid electricity, and assessed the electricity market system dynamics through a survey involving 44 companies, 2 government institutions, and 2 solar energy retailers. The study found that the current offgrid installed generation capacity in Juba is higher than the on-grid with a total of $28.93 \mathrm{MW}$ from 142 generator-sets. $98 \%$ of this amount is diesel-fired and $2 \%$ is from solar. Running these generators for a month cost the companies US\$ 533,204 on 589,760 liters of diesel, and the combustion of this fuel results in $1553.8 \mathrm{tCO}_{2} \mathrm{e}$ emissions. Knowledge of solar energy adoption was low and showed a mixed perception with most companies having no/limited knowledge. Besides, the governance of the electricity market is monopolized by a government utility company without legal frameworks. The study recommends restructuring the electricity market to attract private players by developing legal frameworks and the creation of awareness for the promotion of solar energy.
\end{abstract}

Keywords: Diesel-fired Electricity, Electricity Market Governance, Solar Energy, Off-grid Electricity, Legal Frameworks, Self-generation

\section{Introduction}

Access to modern forms of energy like electricity is crucial in the fight against poverty, as it is among the greatest drivers of socio-economic development of modern society [1]. Yet more than 1.3 billion people in the developing countries have no access to electricity of which 600 million are in subSaharan Africa (SSA), a region with huge energy resources potentials $[2,3]$.

In South Sudan as a country emerging from a long period of conflicts, its unstudied energy sector presents a unique case in the region with an access rate of 5.1\% [4]. Primarily, the economy of the country depends heavily on crude oil exports, which accounted for $60 \%$ of total revenue for the country in 2016 compared to $98 \%$ in 2008 , making it one of the oil-dependent countries in the world [5]. Between 2005 and 2011 for instance, South Sudan earned 13 billion dollars from oil export [6]. However, as observed by Nagy and Szép [7], oil-dependent economies are vulnerable to global oil price uncertainties. This vulnerability has currently resulted into a worse economic crisis in South Sudan with an inflation rate of more than $104.12 \%$ [8], mainly due to the decline in global oil prices since 2014 and reduction in its daily oil production by more than $60 \%$ because of political instability in the country.

Modern urban city design patterns are characterized by high-energy demand and consumption [9-11]. Juba city is South Sudan's commercial and national administrative center with several foreign diplomatic missions, humanitarian organizations, United Nations agencies, and has the highest population compared to other towns in the country. There are also more than 6,000 large, medium, and small-scale commercial enterprises currently operating in Juba [12]. The existence of these institutions and the growing business 
opportunities indicate a growing demand for electrical energy in Juba city. The World Bank ranked South Sudan 187 with zero scores out of 190 economies on the easiness of getting electricity for business operations which implies that, access to electricity and its management is far behind most of the countries in the region.

South Sudan is the largest oil producer with a huge deposit of renewable energy resources (i.e. hydropower, wind, solar, geothermal, and biomass sources) in the region. However, despite these potentials, South Sudan has the lowest electrical energy generation and per capita consumption in Sub-Saharan Africa [6]. The majority of the people live in rural areas and use biomass sources such as charcoal, wood fuel, and grass as their energy sources [13]. On-grid electricity generation is exclusively from thermal diesel generators, which is managed by South Sudan Electricity Corporation (SSEC), a government parastatal company. With an estimated population of 12 million, the projected electricity demand for the country is 300 MW and expected to rise to $1400 \mathrm{MW}$ by $2030[14,15]$. Contrary to the projected demand, only $30 \mathrm{MW}$ installed capacity in isolated locations across the country covering only a total area of $15 \mathrm{~km}^{2}$ is known in South Sudan. Out of this capacity, $22 \mathrm{MW}$ is erratically operational providing electricity to an estimated 22,000 urban-based customers since 2008, and only $12 \mathrm{MW}$ of the operational capacity is in Juba city against growing electricity demand above $154 \mathrm{MW}$ [16]. Empirical data indicates that only $5.1 \%$ of South Sudan population had access to electricity in 2013, with $12.3 \%$ and $3.5 \%$ urban and rural accessibility distribution and a per capita consumption rate of 1-3 kWh compared to $80 \mathrm{kWh}$ average in the SubSahara region $[4,15]$.

The use of diesel-generated electricity has negative impacts on sustainable development as they emit greenhouse gasses (GHGs) that lead to adverse changes in climatic systems and human well-being [17]. Climate change is a major threat to the socio-economic development of South Sudan. Studies indicate that South Sudan is one of the most rapidly warming places on earth with temperatures increasing by $0.4^{\circ} \mathrm{C}$ per decade; a rise that is two and half times higher than the global average. Data on GHGs emissions for South Sudan is currently unavailable. However, USAID [18] claimed that the emission level stands at $1.33 \mathrm{MtCO}_{2}$, which is mainly driven by the massive reliance on biomass (i.e. wood fuel) and fossil (diesel) combustion for energy provision. In 2014, South Sudan acceded to the United Nations Framework Convention on Climate Change (UNFCCC) and submitted its Intended Nationally Determined Contribution (INDC) and National Adaptation Plan of Action (NAPA). Both documents outlined national emissions reduction measures and priority sectors to achieve such targets. In the electricity generation and energy use, for example, the country aims to exploit its renewable energy resources wealth to achieve low carbon and climate-resilient development outcomes [18], as well as generating its projected electricity demand.

A reliable power supply from environmentally friendly sources is paramount for the sustainable economic and social development of South Sudan. Nevertheless, the government continues to face investment challenges for the megaelectricity generation from renewable sources for the on-grid system. On this note, it is indisputable that diesel generators will continue to be the primary source of electricity generation in Juba as evidenced by the recent government's plan to increase electricity generation capacity to $96 \mathrm{MW}$ through the installation of more diesel generators.

Given that diesel-generated electricity is insufficient, unreliable, disruptive to economic development and notoriously expensive to operate and maintain due to rapid volatilities in diesel fuel and spare parts prices, generation capacity in Juba declined rapidly resulting into supply constraints, forced blackouts and load shedding [19], and in 2015, SSEC ceased operations [4]. In response to the prevalent unreliability of the on-grid electricity supply, electricity consumers in Juba opted for off-grid selfelectricity generation using privately owned thermal diesel generators. This practice of self-electricity generation or distributed power generation [20, 21], is increasingly becoming an important source of electricity supply in Juba city despite the economic, social, and environmental impacts it causes.

These private electricity generators in Juba can make a significant contribution to the on-grid system by fitting in their excess power if the current amount of electricity they generate is determined and the design of the electricity market is assessed. The aim of this study was therefore to- (i) assess the generation options and quantify the off-grid electricity generation in Juba; (ii) understand the current state of electricity market design and governance; (iii) analyze the social, economic and environmental impact of private diesel generators and (v) explore various actors' understanding of the potential of solar energy as a step towards energy transition in South Sudan.

\section{Materials and Methods}

\subsection{Study Area}

The study was conducted in Juba the capital of the Republic of South Sudan located at $4^{\circ} 51^{\prime} 05.9^{\prime \prime} \mathrm{N}$ $31^{\circ} 34^{\prime} 56.9 " \mathrm{E}$. Juba also functions as the metropolis of Central Equatoria, one of the 10 states in the country, with an area of $52 \mathrm{~km}^{2}$ and an estimated population of 450,000 people. Juba is divided into three administrative units (Payams), which include Kator, Munuki, and Juba (Figure 1). Like any other city in Africa where much of the economic activities take place, Juba is the economic hub for South Sudan with more than 6000 commercial enterprises ranging from small to large firms [12, 19], and government institutions among others. Juba Payam was chosen for the study based on the high concentration of commercial firms and the demand for electricity. Both Munuki and Kator Payams are mainly residential settlements with fewer business activities compared to Juba. 


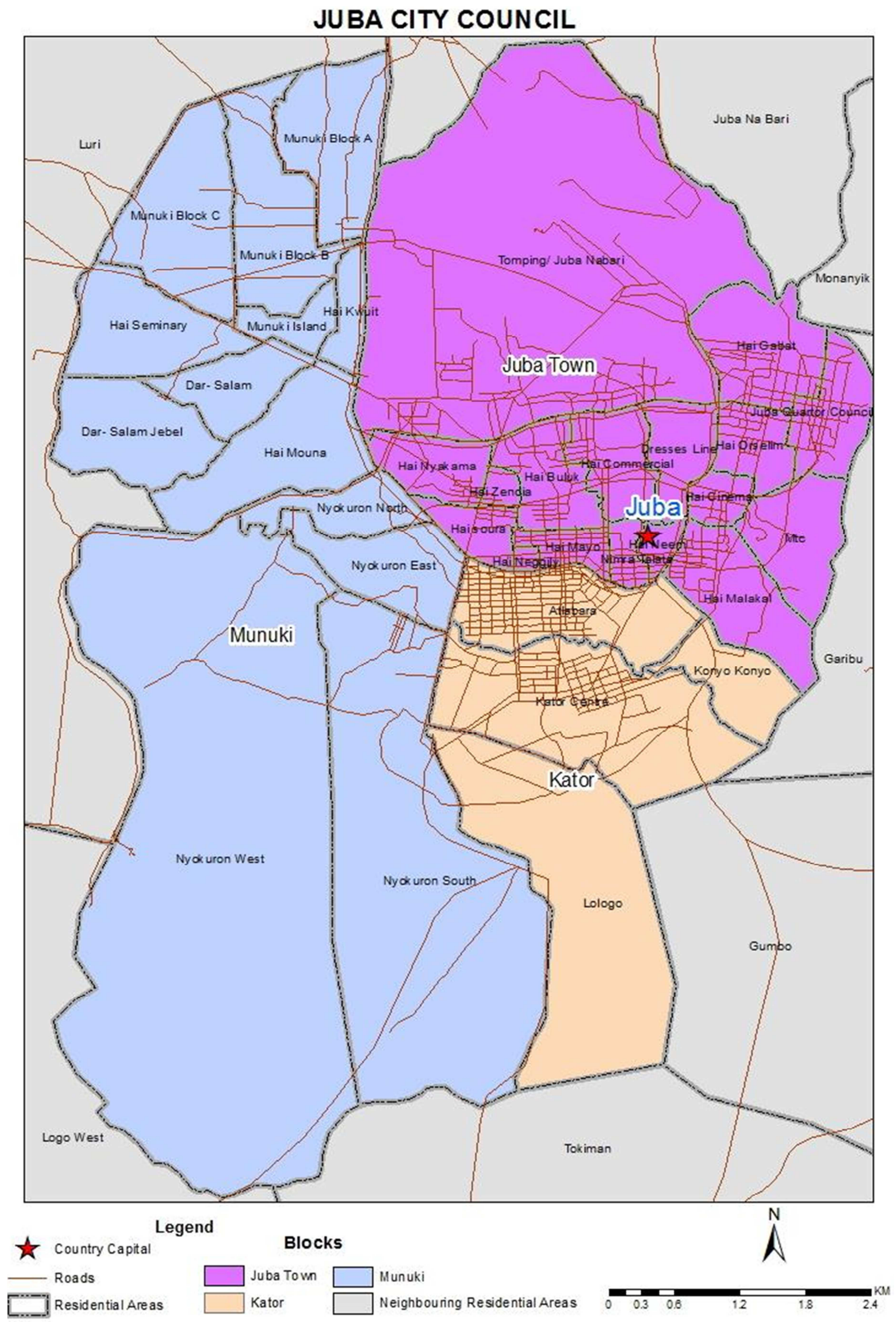

Figure 1. Map of Juba showing the three Payams (Juba, Kator, and Munuki Payam) [22]. 


\subsection{Design and Sampling Techniques}

Before deciding on the sampling procedure for the study, two days were spent on identifying companies present in Juba Payam. An online hotel-booking website (Jumia travel) was also consulted and a list of hotels was drawn based on the address provided. One hundred thirty-six (136) companies were identified and categorized as Hotels, Banks, and Manufacturing based on their lines of operation. Manufacturing companies comprised of those companies that use electricity to make products while Hotels and Banks use electricity for services.

Due to the complexity of studying the whole population, a sample was drawn as suggested by Kadam and Bhalerao [23], using a simple random sampling procedure according to [24] and [25]. However, since the companies are heterogeneous in their operational lines and use of electricity, a stratified sampling method was applied to form several homogeneous subsets (strata) before applying simple random sampling within each stratum [26]. The sample size was then calculated using an online calculator (http://www.raosoft.com/samplesize.html) set at a $90 \%$ confidence level and a confidence interval of $8 \%$. Table 1 . Shows the results of the sampling. To select the participating companies, all the firms in each stratum were assigned a number ranging from 1 for the first firm to " $\mathrm{n}$ " for the last firm in the order of $(1,2,3 \ldots$ n.). Using a mobile phone random numbers generator app (R) available in the google store, the participating companies in each stratum were randomly selected. Besides, two government institutions (i.e. South Sudan Electricity Corporation and the Ministry of Electricity and Dams) and two solar energy companies were selected based on their willingness to participate in the study.

Table 1. Population and Sample size.

\begin{tabular}{llll}
\hline Strata & Population & \% Proportion & Sample size \\
\hline Hotels & 95 & 70 & 42 \\
Banks & 29 & 21 & 13 \\
Manufacturing & 12 & 9 & 5 \\
Total & 136 & & \\
Total percentage & & 100 & 60 \\
Total sample size & & & 6 \\
\hline
\end{tabular}

\subsection{Data Sources and Collection}

The study employed the combination of both quantitative and qualitative data collection approaches according to Kelle [27] and Niglas [28]. A review of relevant secondary literature was also conducted. The quantitative data were collected from the stratified samples between May $7^{\text {th }}$ and $25^{\text {th }} 2018$ using detailed self-administered questionnaires as proposed by Stewards and Cash Jr [29]. Formal interviews were held with key representatives from the stated government institutions and private solar companies using five (5) and six (6) guiding questions respectively.

\subsection{Data Analysis Method}

After gathering all the data from the fieldwork, they were coded and then converted into MS Excel spreadsheet to form a working database and then analyzed using a descriptive statistical method with the help of tables and graphs to visualize trends that underlie the research objectives. The amount of electricity generated was calculated using the formula:

$$
S_{(\mathrm{kVA})}=P_{(\mathrm{kW})} / P F
$$

Where $S$ is the power in kilovolt-amps (kVA), $\mathrm{P}$ is the actual power in kilowatts $(\mathrm{kW})$ and $\mathrm{PF}$ the power factor.

$$
P F=k W / k V A
$$

The recommended power factor for most of the modern diesel engine generators used in this study was 0.8 .

Hence,

$$
P_{(\mathrm{MW})}=P_{(\mathrm{kW})} / 1000
$$

The actual electricity generated in kilowatts hours $(\mathrm{kWh})$ was then calculated as:

$$
k W h=k W * h
$$

Carbon emissions were calculated based on the method of [30] in which,

$$
\mathrm{CO}_{2} \text { Emissions }=\sum_{i=1}^{n} \mathrm{Fuel}_{i} \times \mathrm{HC}_{i} \times \mathrm{C}_{i} \times \mathrm{FO}_{i} \times \frac{\mathrm{CO}_{2}(\mathrm{~m} \cdot \mathrm{w})}{\mathrm{C}_{(m \cdot \mathrm{w})}}
$$

Where:

Fuel $_{\mathrm{i}}=$ Mass or volume of Fuel Type i Combusted

$$
\begin{aligned}
& \mathrm{HC}_{\mathrm{i}}=\text { Heat Content of Fuel Type i }\left(\frac{\text { energy }}{\text { mass or }}\right) \\
& \mathrm{C}_{\mathrm{i}}=\text { Carbon Content of Fuel Type i }\left(\frac{\text { mass }}{\text { energy }}\right) \\
& \mathrm{FO}_{\mathrm{i}}=\text { Fraction Oxidized of Fuel Type } \mathrm{i} \\
& \mathrm{CO}_{2} \text { (m.w) }=\text { Molecular weight of } \mathrm{CO}_{2} \\
& \mathrm{C}(\mathrm{m} \cdot \mathrm{w})=\text { Molecular weight of Carbon }
\end{aligned}
$$

The emitted carbon was presented in kilograms (kgs) by first ensuring that the amount of fuel combusted in liters is converted into $\mathrm{kg}$ by a simple mathematical formula as follows:

$$
\text { Fuel }_{(\mathrm{kg})}=\mathrm{Fuel}_{(\mathrm{L})} \times 1.1764
$$

The qualitative data was analyzed based on relevant themes and the findings were used for addressing governance questions and strengthening the discussion of the findings.

\section{Results}

\subsection{Private Electricity Generation in Juba}

The electricity generation in Juba city is thermal based on diesel generators. In assessing the capacity of the off-grid electricity in terms of Megawatt (MW), the kVA rating of the generators and the power factor (PF) were taken into consideration. Forty-four companies were surveyed, and the study found that the companies had installed a total of 142diesel generators onsite. The hotel sector has the highest number of generator sets $(58.5 \%)$ and generation capacity $(62 \%)$. Detailed analysis of the other sectors (banking and manufacturing) showed that, despite having more diesel generator sets, the banking sector's generation capacity is less 
than that of manufacturing. This can be attributed to the fact that most of the banks operate for eight hours daily during working days, as they do not have functional ATM cash machines available at the time this study was conducted. Table 2 below summarizes the results of private off-grid electricity generated in Juba.

Table 2. Off-grid private electricity generation in Juba.

\begin{tabular}{|c|c|c|c|c|c|c|c|}
\hline Strata & \# companies & $\begin{array}{l}\text { \#Diesel Gen- } \\
\text { set }\end{array}$ & $\begin{array}{l}\text { Hours } \\
\text { run/Month }\end{array}$ & $\begin{array}{l}\text { Gen-set Capacity } \\
\text { (kVA) }\end{array}$ & $\begin{array}{l}\text { Solar capacity } \\
(\mathbf{k W})\end{array}$ & $\begin{array}{l}\text { Power } \\
(k W)\end{array}$ & $\begin{array}{l}\text { Power/Month } \\
\text { (kWh) }\end{array}$ \\
\hline Hotel & 29 & 83 & 17790 & 22034 & 320 & 17627.2 & 313587888 \\
\hline Bank & 11 & 39 & 3925 & 5749 & - & 4599.2 & 18051860 \\
\hline Manufacturing & 4 & 20 & 2520 & 7675 & 240 & 6140.0 & 15472800 \\
\hline Total & 44 & 142 & 24235 & 35458 & 560 & 28366.4 & 347112548 \\
\hline
\end{tabular}

The study also found that the total installed capacity of the off-grid electricity generation is $28.93 \mathrm{MW}$. Ninety-eight percent $(98 \%)$ of this capacity is diesel-fired and only $2 \%$ is solar-generated. The hotel sector dominates the off-grid generation capacity with diesel generators being the main source of electricity generation.

A close analysis of the different strata/sectors under this study further revealed that of the $2 \%$ installed solar system, $57 \%$ was in the hotel sector used for lighting and heating, while $43 \%$ is in the manufacturing sector. The Banking sector uses $100 \%$ diesel-fired electricity for all its operations. Figure 2 below shows the breakdown of the total installed capacity by strata and energy source respectively.

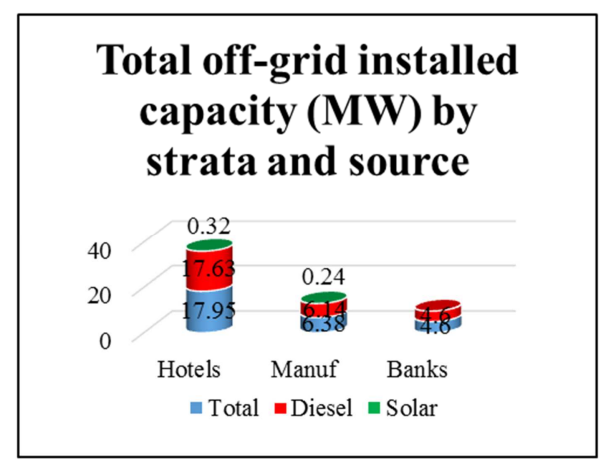

Figure 2. Total installed capacity by stratum and source of generation.

\subsection{Electricity Market Governance Systems}

The electricity market governance refers here to how governments exercise their political, economic, and administrative authority, including the mechanisms, processes, and institutions to manage the entire electricity value chain. The electricity governance according to
Goldthau [31], encompasses its embeddedness within and coevolution with the socioeconomic institutions, regulatory agencies, incumbent market actors and social norms; the multiple scales of sustainable infrastructure solutions; and the existence of elements of common-pool resource problems.

This study found that governance of the electricity sector in South Sudan can best be described at two levels that include institutional and policy arrangement and regulatory framework.

\subsubsection{Institutional and Policy Arrangements}

Regarding the institutional governance of electricity, South Sudan's electricity-related intuitions are still at their embryonic stage. The Ministry of Electricity and Dams (MoED) is the main institution responsible for governing the electricity sector. Its core mandate is to formulate policies and strategies related to the management and development of the electricity sector including resource mobilization to diversify the generation options. The government parastatal utility, South Sudan Electricity Corporation (SSEC) is the immediate institution whose mandate is centered around electricity generation, transmission, and distribution as well as electricity revenue collections and purchase of electricity from independent power producers (IPPs). The performance of SSEC is regulated by MoED, which also sets tariffs for electricity distribution in collaboration with the Ministry of Finance and Economic Planning (MoFEP).

Other institutions directly or indirectly involved in the electricity sector include the State Electricity Distribution Companies (SEDC); Ministry of Petroleum (MoP); Ministry of Commerce, Industry and Investment (MoCII) and the Ministry of Environment (MoE). Table 3 summarises the roles played by each of these institutions in the electricity sector.

Table 3. Summary of electricity governing institutions in South Sudan.

\begin{tabular}{ll}
\hline Institutions & Roles and Responsibilities \\
\hline \multirow{2}{*}{ SEDC } & $\begin{array}{l}\text { Manages and operates the local electrical power distribution services at the state levels by facilitating the work of rural electricity } \\
\text { cooperatives and community-owned and operated distribution entities. It also licenses these rural entities to develop, finance, and operate } \\
\text { decentralized electricity generation systems in consultation with MoED. }\end{array}$ \\
It is responsible for financing the operational costs and investments in new generation projects. $80 \%$ of the electricity revenue is directly \\
controlled by this institution and it sets all procurement procedures that SSEC must follow in the event of procuring any equipment. \\
In collaboration with MoFEP, MoP is responsible for importing and supplying diesel to SSEC for running the generators sets through its \\
aligned commercial entity NilePet corporation which controls the sale of fuel like diesel, petrol, and kerosene in the country. \\
Responsible for the protection and management of the environment. When it comes to issues of climate change resulting from electricity \\
generation such as carbon emissions, MoE collaborates with MoED in regulating the practice, as it's the only entity with the mandate of \\
reviewing the environmental social impact assessment (ESIA) plans of projects and issuing environmental compliance permits. \\
In coordination with MoFEP, its responsible for setting import taxes for all products entering South Sudan including energy-related products \\
indiscriminately
\end{tabular}


Despite the existence of these institutions, they have not worked to improve the performance of the electricity sector in South Sudan. According to SSEC, lack of consistent supply of fuel, generators spare parts, irregular maintenance, and high fuel consumption rates affected the electricity generation and supply. The government also subsidizes the electricity tariffs by more than $60 \%$, and MoFEP retains $80 \%$ of the collected revenue, which is always less than the total investment. This makes planning difficult for SSEC due to bureaucratic financial procedures of the finance ministry.

\subsubsection{Policy and Regulatory Framework}

The analysis of the policies and regulatory frameworks for governing South Sudan's electricity sector indicated that most of the legal instruments are either in draft forms or proposed ideas. The policies originate from the May 2007 South Sudan National Electricity Policy (SSNEP) paper that outlined the framework for the development of the Electricity Supply Industry (ESI) including strategies for Public-Private Partnerships (PPPs).

The most relevant policy document is the draft South Sudan Electricity Bill of 2010 that is yet to be approved by the council of ministers. The Bill provides for the establishment of an effective governance system for the electricity sector through the formation of an independent regulator the "South Sudan Electricity Regulatory Authority" (SSERA) to (i) Regulate the electricity market by granting licenses; (ii) Review and approve all electricity tariffs; (iii) monitor the functioning of the electricity market and enforce necessary standards; (iv) Facilitate disputes resolutions; and (v) prevent the tendency of electricity market monopoly. Other related draft policies include the Electricity Act, Electricity Sector Strategic plan, Electricity Licensing Regulations, and the National Environmental Bill. Without the enactment of these policy instruments, South Sudan's electricity sector will undoubtedly continue to operate in an unregulated environment, which may limit the chances for any private investment in the sector.

Furthermore, in all the draft policy documents, no sentence outlines a specific strategy for future promotion of Renewable Energy Technologies (RETs) and Energy Efficiency (EE) in the electricity sector. Similarly, regulatory modalities such as Fit In Tariff (FIT) or Power Purchase Agreements (PPAs) that could play an important role in attracting private investment into electricity generation, distribution, and transmission are not currently available in South Sudan. Additionally, no legal mechanisms now exist for regulating parallel power generation and supply to the grid system or installing a private diesel generator. Although SEDC has highlighted the importance of IPPs in the sector, it does not provide distinct details on their regulation.

Asked about the challenges of operating the sector without legal and regulatory frameworks, SSEC asserted the extreme difficulty and lamented that, the distribution network in Juba city has many illegal connections and without law in place, it cannot punish those involved in the illegal connection except only disconnecting them from the distribution lines without demanding compensation for the electricity they have used due to the absence of specific law for the sector.

\subsection{Socio-economic and Environmental Impact of Diesel Generators}

In countries where reliable electricity is daunting, diesel generator sets have become the immediate sources for generating electricity. However, the increase in the cost of diesel fuel is making it more expensive to sustain electricity generation, which consequently deters economic growth in those countries with heavy reliance on generators because emerging enterprises are always put off by the high electricity cost. Additionally, running diesel generators causes social and environmental impacts, which eventually lead to serious health-related issues.

\subsubsection{Socio-economic Impact}

Running diesel generators is noisy and can create severe discomfort to societies and businesses. Out of the 44 companies surveyed in this study, $37 \%$ reported social issues related to the operation of the diesel generators (Figure 4). These issues include complaints from both customers and the neighborhoods regarding continuous noise that is more likely to leads to serious mental and emotional stress. There is also an abrupt breakdown of the system, which disrupts their social wellbeing. Additionally, the existence of the generator sets in the compound occupies social spaces.

Despite being regarded as the optimum solution for persistent electricity outages or off-grid rural electrification programs, the economic costs associated with operating diesel-fired electricity generation is excessively high. To generate electricity for one month, the surveyed companies require up to 589,760 liters of diesel which amount to a total of US\$ 533,204; excluding maintenance costs to keep the generators running. The hotel industry is the biggest consumer of diesel fuel and thus more expenditure standing at $78.4 \%$ and $78.7 \%$ respectively. In the banking sector, $73 \%$ of the participants reported an abrupt breakdown of the generator sets during business operation and the complete absence of diesel fuel in the market causing financial losses and growing anger from customers. Figure 3 below shows the breakdown of the economic costs of running generator sets for electricity generation with hotels almost quadrupling the manufacturing and banking sectors.

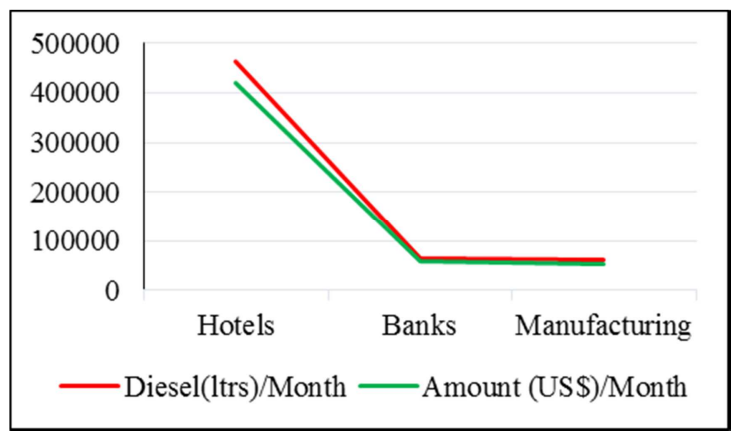

Figure 3. Monthly fuel requirement against costs. 


\subsubsection{Environmental Impact}

The use of diesel fuel for electricity generation emits several GHGs into the environment that has human and environmental health implications. Studies have estimated that more than 40 toxic air pollutants with some linked to or suspected to cause cancer, as well as environmental degradation, are known to have been emitted through diesel exhaust [32].

Despite the global environmental impacts of operating diesel generators, only $18 \%$ of the companies in this study reported experiencing environmental issues such as air and property pollution due to black smoke, leakage of oil on the ground surface, and drying of trees and flowers close to the generators. $45 \%$ have no knowledge of any environmental impact of operating diesel generators.

To better understand the environmental and health risks associated with diesel-fired electricity generation in Juba, the carbon emission footprint of private electricity generation was determined. The results showed that the environmental impact of diesel-generated electricity in Juba is so severe as indicated in Table 4. More than 1553.8 tons of carbon dioxide $\left(\mathrm{CO}_{2}\right)$ equivalent is being emitted into the air monthly with the hotel sector accounting for $78 \%$ of the total emissions.

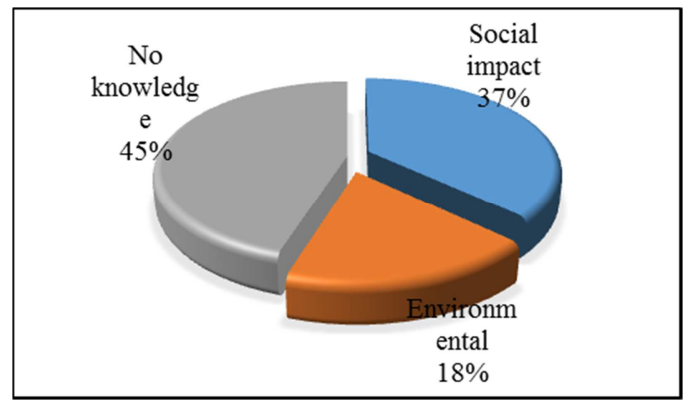

Figure 4. Social and Environmental impact knowledge.

Table 4. Total $\mathrm{CO}_{2}$ emission from diesel generators in Juba.

\begin{tabular}{llll}
\hline Strata & Fuel combusted/ month (Itr) & Fuel combusted/ month (kg) & kgCO/ month \\
\hline Hotels & 452420 & 384580 & 1212491 \\
Banks & 65840 & 55967 & 176452 \\
Manufacturing & 61500 & 52278 & 164821 \\
Total & 579760 & 492825.6 & 1553763 \\
\hline
\end{tabular}

\subsection{Potential of Solar Energy Integration into the Electricity Mix}

The potential of solar energy in South Sudan is huge and is estimated at approximately $6.9 \mathrm{GJ} / \mathrm{m}^{2} /$ year with an average of 8 hours of sunshine per day. There is currently no data on the exploitation of solar energy for the on-grid electricity generation system in the country.

In this study, we also assessed the knowledge and willingness of the companies to incorporate solar PV systems into their electricity generation. The results showed that only $36 \%$ (Figure 5) of the respondents have basic knowledge of solar energy and its importance for electricity generation. This knowledge concentrated on costs and emissions reduction benefits compared to diesel generators and a reduction in the level of complaints from the neighborhoods about continuous noise and smoke from the generator sets. The lack of knowledge about solar energy was high (64\%) among the respondents.

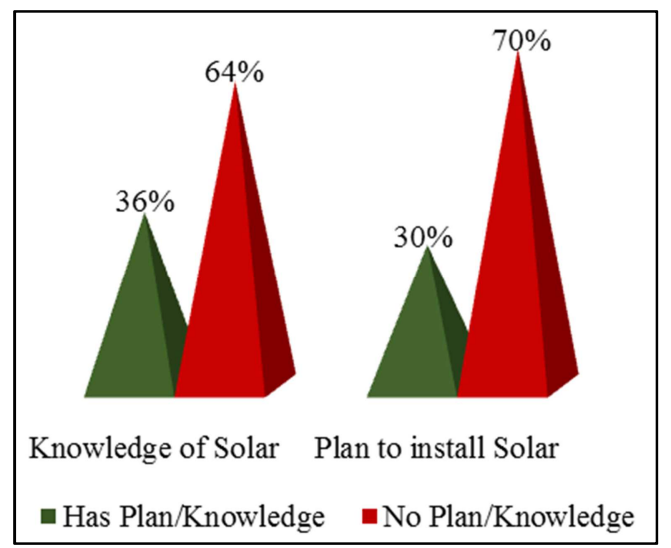

Figure 5. Knowledge of solar energy against plan to install a solar system.
Asked whether they would consider installing a solar system to alternate with the diesel generators, the study found only $30 \%$ (Figure 5 ) of the companies have plans to install a solar system in the future. The majority of the companies (70\%) expressed lack of interest in solar energy due to three main impediments including (i) the high cost of initial installation in the absence of any financing mechanisms in South Sudan (ii) the capacity of the solar system may not match the load demand for their businesses coupled with unpredictable weather conditions leading to economic losses and (iii) installing a reasonably good solar system requires a large space compared to the space for generators. Additionally, Juba has a high theft rate of solar panels in South Sudan. For instance, the panels installed by the government for street lighting in 2015 disappeared in a couple of months. Hence, installing solar systems within business premises is perceived as a source for attracting thieves to rob the companies.

Nevertheless, those who have already installed some solar system reported financial savings from diesel fuel purchase as the system can effectively run lightings, some fridges, TV sets, and provision of warm water for some hours during the day. One private solar company reported the existence of huge market demand for the solar system. In 2015 for instance, it sold out 1MW solar equipment to NGOs and individual clients. However, the sales declined in the subsequent years to an average of $800 \mathrm{~kW}$ per annum due to conflict and economic crisis in South Sudan that eroded the purchasing power of the clients.

\subsection{Participation in Electricity Trading}

In the developed economies with well-established stock 
markets, electricity can be traded in the financial markets like any other commodity to help traders diversify their investment and revenue. In these marketplaces, electricity must be generated, transported, delivered, and used continuously by the final users. Yet to ensure this continuity, the electricity supply must always match demand.

An effective and functioning electricity market brings together several generators, suppliers, and system operators who compete among themselves so that customers can choose a supplier of their choice, suppliers choose a generator they prefer, generators improve their generation in order to be chosen and system operators improve the efficiency of their transmission infrastructure. We, therefore, assessed the current plans of companies in Juba regarding their participation in electricity trading using four different parameters (i.e. Buying, Selling, Both, and Not interested) to measure the companies' perspectives. The results showed four different perspectives as illustrated in Figure 6 below.

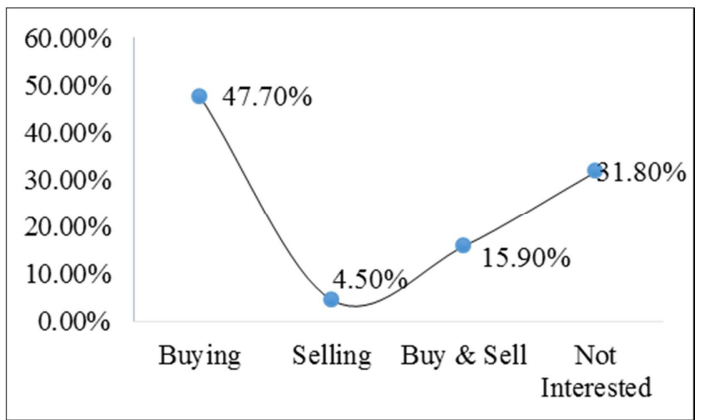

Figure 6. Companies willingness' to participate in the electricity market.

Based on the four parameters, we found that $47.7 \%, 4.5 \%$, and $15.9 \%$ of the companies are interested in buying, selling, and both (i.e. buying and selling) respectively. However, $31.8 \%$ showed no interest in buying or selling electricity and preferred self-generation and consumption option because: (i) external suppliers are currently not reliable in Juba and depending on transmitted electricity can be destructive to business operations and (ii) the current capacities of their installed diesel generators are sufficient to supply the required amount of electricity for their businesses.

To sell privately generated electricity to consumers requires access to the grid system to facilitate its transmission. With over $47 \%$ of the companies ready to buy electricity, there is a potential to diversify generation and electricity supply systems in Juba when the companies are given access to the grid network. At the sectoral/stratum level, $100 \%$ of the companies willing to sell electricity are from the hotel sector. These companies seem to be seeking new ventures to diversify their business portfolios given the existing market opportunities.

\section{Discussions}

\subsection{Electricity Generation Options and Supply}

South Sudan has the potential to diversify its electricity mix by developing the available renewable energy resources wealth and sustainably electrifying Juba. Diversification in this sense means developing an energy trajectory away from the incumbent diesel based. More than $60 \%$ of the country's hydropower potential, for instance, is located within the vicinity of Juba city [19] which makes it easy to connect directly to the transmission line.

Juba has an official installed generation capacity of 12 MW exclusively from thermal diesel generators against a growing electricity demand of $154 \mathrm{MW}$ [16]. This demand poses a challenge to the electricity sector due to insufficient generation and supply capacity of SSEC causing continuous blackouts and load shedding that distresses social comfort and derail business development. The transmission and distribution (T\&D) networks are also inefficient. Even though these are considered as challenges from the electric utility perspective, they are opportunities from the Prosumers' perspective as they become fully in charge of the management of their electricity demands and supply.

The 28.93 MW off-grid capacity owned by the 44 companies demonstrated the potential of incorporating Prosumers with excess electricity into the electricity supply in Juba to meet the growing demand that SSEC is unable to supply. Diesel generators are still the main choice for off-grid electricity generation in developing world due to their convenience and low cost of installation [33, 34], thus, the World Bank [14] recommends their use in the short-term until the time South Sudan can secure financial resources to invest in other sustainable generation options. As an oilbased economy, South Sudan can avoid the impact of the global oil price crisis on its electricity generation by directly utilizing crude oil as in Saudi Arabia [35]. However, this option also comes with massive environmental consequences if explored without proper regulation mechanisms in place.

The solar energy potential of South Sudan stands at $6.9 \mathrm{GJm}^{2} /$ year or $5.0 \mathrm{kWh} / \mathrm{m}^{2}$ with daily sunshine of more than $8 \mathrm{hrs}$ throughout the years $[16,36,37]$. The exploitation of this potential can be seen in street lighting, public infrastructure (i.e. offices, schools, and hospitals) as well as some residential housing across the country [15, 37, 38]. Scaling these initiatives to a much higher level of electricity generation can have a significant contribution to the grid system.

The production of biomass and other organic wastes in the country are also huge, estimated to be 75 million hectares of forests based [39, 39], and 4.5 million tons of livestock waste [38]. Juba generates about 416 tonnes of waste every day [40], and with an appropriate application of waste to energy technologies, the biomass potential can have a significant contribution to Juba electricity generation mix and hence, increase electricity access within the city.

Additionally, with its approximate located in the East Africa rift valley like Kenya with $45 \%$ installed geothermal energy capacity, South Sudan can utilize its geothermal energy potentials in the oil wells along the Bahr el Arab area [41] for electricity generation.

Electricity generation can also be diversified not only in 
terms of sources but also in those involved in the generation. SSEC currently monopolizes the generation, transmission, distribution, and sales of electricity in South Sudan. However, with a conducive environment and effective governance systems in place, some of the companies that participated in this study could be involved in the electricity generation and supply having expressed their willingness.

\subsection{Diesel Generators and the Socio-economic and Environmental Impacts}

The adoption of diesel generators in the off-grid electrification program continues to grow in Africa. More than $6 \%$ of the installed generation capacity of Sub-Sahara Africa, for instance, is made up of self-generation mainly using diesel generators [42]. Previous studies estimated that Juba has between 5000-10000 small and medium-size diesel generators with varying power output capacities [15]. We, however, found 142 diesel generator sets in addition to the reported 195 sets with the UN Mission in South SudanUNMISS [6]. As the number of businesses continues to grow rapidly in Juba with erratic electricity supply, the number of diesel generators must have increased higher than previous estimates.

The proliferation of diesel generators for electricity generation has become a major concern for the government in Juba as it attempts to fulfill its commitments to the Paris Agreement on climate change. Diesel generators have damaging effects on the environment, people's health, and quality of life [43]. Communities living near to the generation power plant are likely to suffer from endless sound from the running generators. Thirty-seven percent (37\%) of the companies involved in this study reported having experienced complaints from the neighborhoods and their customers because of noise, smoke, and unnecessary heat.

Furthermore, the combustion of diesel fuel emits dangerous pollutants into the air that can affect human health causing several respiratory diseases [30]. Gasses like carbon dioxide $\left(\mathrm{CO}_{2}\right)$, nitrogen oxide ( $\left.\mathrm{NOx}\right)$, sulfur dioxide $\left(\mathrm{SO}_{2}\right)$, and methane $\left(\mathrm{CH}_{4}\right)$ released by generators are potential GHGs that are responsible for the rise in global temperature above average. The 44 companies in Juba alone are responsible for an equivalent of 1553.8 tons of carbondioxide $\left(\mathrm{CO}_{2}\right)$ monthly based on the figures of diesel fuel consumption reported. This suggests that the carbon emission from private electricity generation in Juba is higher than expected. Even beyond direct health concerns, pollutants such as black soot, sulfur oxides (SOx) and heavy metals in diesel exhaust or oil leakages from storage facilities can lead to soil and water pollution which subsequently affects water retention ability of the soil and plants extraction of nutrients from the soil [44]. In the long run, this can affect urban farming for food production with the worst-case scenario when the pollutants cross into the food chain through food crops or livestock consumed in the city.

Becoming electricity Prosumer using fossil fuels is extremely expensive than purchasing power from the public grid system [42]. For the 44 companies in Juba to supply their monthly electricity demand, 589,760 liters of diesel fuel are needed which equates to US\$ 533,204; apart from maintenance costs. SSEC's $12 \mathrm{MW}$ in Juba consumes as much as 10,000 liters per day yet only $33.3 \%$ of the monthly 60 million liters of diesel fuel imports required for the entire country are available [45]. This supply shortage caused severe fuel crisis in Juba between 2014 and 2017 and led to the emergence of fuel black markets across the country [6, 46]; followed by a rapid increase in local prices. According to one hotel manager, the price for a hotel in Juba is also determined by the price of diesel fuel in the market; and when the markets are out of fuel, they shut down the business because electricity is core to their operations.

This economic burden of own-electricity generation in Juba agrees with the finding of Mozersky and Kammen [6], who reported that between 2011 and 2014, UNMISS consumed 68.7 million liters of diesel fuel for both electricity generation and transportation, which cumulatively amount to US\$ 325 million. This consumption presents a significant environmental, social, economic, and health risks as well as setting spotlights on the role of humanitarian agencies in carbonizing South Sudan.

\subsection{Solar Integration and Its Role as South Sudan's Model for Energy Transition}

Solar energy could be South Sudan's immediate and costeffective energy trajectory for sustainable energy transition and peace promotion by creating jobs for the youth if exploited [6]. Compared with the hydropower potential, solar expansion is feasible since hydropower development requires a large investment in both generation and infrastructure; and given the fact that more than $80 \%$ of South Sudanese live in the rural areas, extending the national grid to those scatter villages will take decades to complete if at all the financial resource was to be secured.

South Sudan receives an average of 8 hours of sunshine daily, which produces an estimated $436 \mathrm{~W} / \mathrm{m}^{2} /$ year of energy [37]. This sunshine potential is adequate to generate electricity that can out-compete the current diesel generators because it is clean, cheap, and long-lasting. The two percent $(2 \%)$ of the companies that have integrated solar system into their businesses confirmed financial saving as a result of solar energy integration. With the experience of continuous electricity blackouts lasting for days if not months, consumers have begun the transition journey towards solar energy. From 2014, the number of households in Juba acquiring solar systems rose above the number of those acquiring diesel generators according to a study by Tiitmamer and Jok [4]. The demand for solar is growing within and outside Juba and through the presence of the international organization and UN agencies like UNICEF, long term contracts (approximately three years long) have been made with solar companies for the supply of various solar systems. Estimations of solar penetration showed that there are currently more than 54000 households in South Sudan using different forms of solar devices including state 
government's streetlights in Juba and Maridi towns and water pumps in several other locations countrywide [15].

In addition to the sunshine potential, several other factors contribute to making solar as a model for energy transition in South Sudan by taking on the lead over the incumbent diesel generators. At the micro-levels, the inefficiency of grid electricity supply and changing living standards among the members of the public make electricity consumers turn towards solar energy installation. The second most important factor can be broken into three as follows:

Firstly, South Sudan receives millions of donors' funds annually for humanitarian activities of which a portion is spent on diesel fuel for both electricity and transportation. These funds can pave solar energy transition in the country. The initial establishment and expansion of solar market in Kenya to the point that in 2012 it became the world's second after China in Solar Home Systems (SHS) installation was through donor-led intervention [47]. South Sudan with the current donors' activities would harness rigorous support for the development of solar energy. UNICEF and UNDP have already installed several solar systems on public infrastructure like schools, health care units and hospitals, and USAID has switched a community radio, Mayardit 90.7 FM in Turalei from diesel-generator to a $100 \%$ solar PV [48].

Secondly, donor-led solar energy transition from the humanitarian perspective has successfully worked in Jordan refugee camps [49]. With the current Internally Displace Persons (IDPs) and refugee crisis in South Sudan, a transition from the predominant biomass use to solar energy could be championed by humanitarian agencies through the means of local capacity building and establishment of demonstration projects that could generate demand for PV, thus saving the environment and existing forests in the refugee settlements. In the long run, however, the government and the host communities would benefit from solar infrastructure in the post refugee era, which can lead to the emergence of community-based electricity prosumers.

Thirdly, there is limited environment protection mainstreaming into humanitarian programming. A slight trigger by the donors against agencies' diesel fuel-based energy plans in favor of renewable solutions (solar PV) can cause rapid solar energy installation by all humanitarian agencies now operating in South Sudan.

Nevertheless, to facilitate this transition, removing curtails along the pathway such as excessive taxes, poor solar knowledge and, lack of financing mechanisms will be desirable. Solar energy retailers have reported a lack of knowledge regarding solar energy in South Sudan as justified by the fact that this study found $63.6 \%$ of the companies had no idea about the importance of solar energy.

\subsection{Electricity Market Design and Governance}

The electricity market is the major underlying factor that determines any functioning of the power system. Modern market designs focus on reliable electricity systems that provide electricity to end-users at least costs [50], through a liberalized market where participants can jointly invest in electricity supply. As Bublitz et al., [51] noted, electricity markets are in a transitioning phase characterized by an increasing share of renewable energies. However, this development has only come to supersede the past electric power systems that relied on generators to supply consumers' energy demands.

Data derived from the draft South Sudan Electricity Bill and backed by the discussions held with the institutional stakeholders showed that SSEC is legally responsible for the administration and management of the national grid systems for power transmission and distribution, purchase of power from IPPs and setting electricity tariffs in collaboration with MoED and MoFEP. This demonstrates the vertical integration of the electricity sector in South Sudan. As a vertically integrated market design with only SSEC as the sole player in the generation, transmission, distribution, and system operation, it faces many discrepancies specifically in the amount of electricity generated, billed for by the utility, and the actual amount paid. In 2011, SSEC generated 99 GWh of electricity at a cost of US\$ 71 million. However, it only sold $70 \mathrm{GWh}$ at US\$ 17 million making a loss of $76.1 \%$ of the total investment [14].

This financial loss is in part due to inefficient grid systems with losses estimated at $30 \%$ and electricity theft from the transmission line as well as non-payment of bills mainly by high ranking government officials. Due to insufficient funding, SSEC has limited capacity to develop the grid system or invest in the generation and capacity development of its staff. This scenario agrees with Strbac and Wolak [52] who state that most vertically integrated electricity markets in the developing countries are state-owned with a poor history of providing a reliable supply of electricity and usually have huge difficulty in raising the capital needed for investments in electricity market supply systems.

In liberalized electricity markets, however, markets are designed to be able to deal with most of the impediments experienced in the vertically integrated market design to ensure efficiency, reliability, and transition towards sustainable low carbon-emitting energies [53]. Even if such an approach could be incorporated into the South Sudan electricity market, SSEC has neither the experience in dealing with a private connection to the grid system for electricity supply nor technical skills in the metering system for revenue collections. The present prepaid metering devices used in Juba are remotely controlled from South Africa. This, in addition to the absence of legal regulatory frameworks, can significantly obstruct the establishment of a viable electricity market. Even with the US\$ 17 million funding from the African Development Bank for the rehabilitation and expansion of Juba transmission and distribution network and capacity development [19], maintaining a functional electricity market in South Sudan will not be sustainable because of state involvement and lack of incentive mechanisms.

Direct state involvement in the electricity market if not strategically crafted can introduce a paralyzing power against the development of the market as in the case of South Sudan. 
SSEC's produces one $\mathrm{kWh}$ at a cost of $0.70 \$$. However, the government crippled SSEC's operation capability by introducing nonviable electricity subsidies of $0.54 \$(70 \%)$ per $\mathrm{kWh}$ of the generated electricity making customers pay only $30 \%$ of the production cost. This subsidy not only destroys the electricity market but also stresses the country's annual budget by $40 \%$ [54]. In addition to the state interference, there also exists a complete lack of transparency in the collection of electricity bills by SSEC where continuous disappearance of cash within the finance offices has persisted without any sort of accountability. The finance officers are believed to have opened private bank accounts to which they direct some customers to deposit their electricity bills (Personal comm. SSEC) causing a significant difference between electricity sold and actual revenue collected.

Despite its internal financial issues and the collapsing power of subsidies, SSEC argues that its inability to maintain generation is caused by MoFEP, which controls $80 \%$ of revenue collected because any financial request made to the ministry to procure diesel fuel or generator spare parts takes more than three months to be approved. Nevertheless, this challenge is a feature of any vertically integrated market under the monopoly of one player with direct state influence. As stated by Shen and Yang [54], this kind of market limits competition, innovation, and efficiency if not unbundled. Hence, co-supplying the grid by private producers is not feasible in the context of South Sudan where the whole sector is under state influence and run without legal governing instruments.

The electricity market under the monopoly of a state-own utility like that of South Sudan could be liberalized through horizontal integration and introducing a system of incentives such as PPAs and FITs to bring into play various IPPs. Unfortunately, all known incentive modalities currently applied in all electricity markets and energy transition mechanisms are missing in South Sudan. As a new emerging market with all legal frameworks in draft forms, attracting IPPs to participate in a state monopolized market will undoubtedly take a long period to evolve to a fully liberalized market where the private suppliers can become active players in all aspects of the electricity value chain.

\section{Conclusion}

South Sudan is among the few SSA countries blessed with an abundance of both renewable and conventional (oil) energy resources. The socio-economic development of the country rests on oil extraction and exports. Despite its renewable energy resources potential, electricity generation is exclusively oil-fired with SSEC as the only player in the electricity market. However, SSEC's generation capacity is inadequate compared to the electricity demand of Juba. These disparities consequently lead to continuous electricity outages and load shedding that disrupts social comfort and businesses. Hence, pave ways for onsite self-electricity generation using diesel generators.

Juba currently has a high installed off-grid electricity capacity than that generated by SSEC. The hotel businesses owned the largest portion followed by the manufacturing companies. Some of the companies generate more electrical power than they needed, which indicates a potential for supplying the grid system. Although there is solar energy penetration in Juba, its contribution to the electricity mix is less and there are no promotional programs in place to raise public awareness on the importance of solar energy despite the abundance of sunshine.

There is more emphasis on the installation of diesel generators for electricity supply in Juba. Nevertheless, dieselbased electricity has a huge burden on companies, society, and the environment. For instance, the companies spend US\$ 533,204 on diesel fuel alone to run their generators each month. Additionally, running the generators produce endless noise and smoke full of dangerous gases, which cause pollutions that threaten people's health and the environment. Adoption of solar could be a remediating strategy for the socio-economic and environmental issues now superseding the electricity generation in Juba. Unfortunately, knowledge regarding the importance of solar energy is low among companies, as most of them prefer using diesel generators than adopting solar energy.

South Sudan has a woefully unsatisfactory electricity market governance system with a prevailing sense of political interference. Despite having institutions mandated to govern the electricity sector, these institutions generally lack the legal instruments for managing the sector. The drafts of the legal frameworks that could help in transforming the sector have ended up in the council of ministers' desks for the last six to eight years without approval for use. The absence of legal frameworks governing the electricity market makes it extremely complicated for the current electricity Prosumers in Juba to fit in their excess electricity to the national grid. SSEC, which is responsible for the administration of the grid and metering system, is a vertically integrated entity with a direct influence of MoED and MoFEP. The high bureaucracy in these institutions can make private suppliers of electricity to the grid system to incur payment irregularities or losses.

There are currently more donor funds flowing into South Sudan for humanitarian activities. Hence, solar energy can become the best transitioning option for sustainable energy through an effective humanitarian renewable energy mainstreaming, which ensures that the current humanitarian beneficiaries become future electricity entrepreneurs in the generation and management of the established transmission and distribution networks.

On this note, we recommend that the government enact all the draft legal instruments, remove the huge subsidies, and introduce FIT and PPA mechanisms to attract IPPs. Restructure the electricity market to avoid monopoly that affects electricity quality and consumers' satisfaction is a key priority. Develop a ministerial partnership comprising of MoE, MoED, and the Ministry of Health $(\mathrm{MoH})$ to raise public awareness on the socio-economic, health and environmental dangers of diesel-based electricity and the importance of solar as an alternative clean energy source. 
Finally, the humanitarian organizations operating in South Sudan with excessive diesel fuel consumption for electricity and transportation should mainstream renewable energy into their programming strategies to reduce their carbon footprint and set clean energy platforms for the local communities.

\section{Acknowledgements}

We acknowledge the support from the Open Society Foundation and Central European University Foundation for funding the study. We also appreciate the courage of the respondents who despite the sensitivity of research in Juba were able to provide crucial data.

\section{References}

[1] Azodo, P. A. (2014). Electric power supply, main source and backing: A survey of residential utilization features in Obantoko, Ogun State, Nigeria. Annals of the Faculty of Engineering Hunedoara, 12 (4), 51.

[2] IEA (2018) World Energy Outlook (2018). IEA, Paris.

[3] Rosnes, O. and Vennemo, H. (2008). Powering Up: Costing Power Infrastructure Investment Needs in Southern and Eastern Africa- World Bank Africa Infrastructure Country Diagnostic Paper No. 61813. [Online]. Available: http://www.eu-africa-infrastructure-

tf.net/attachments/library/aicd-background-paper-5-powerinvest-summary-en.pdf [Accessed 17 June 2018].

[4] Tiitmamer, Nhial, and Jok Gai Anai. (2018). Transitioning to Renewable Energy: An Analysis of Energy Situation in Juba, South Sudan. Sudd Institute

[5] UNEP (2017). Energy profile for South Sudan. In Atlas of Africa Energy Resources. Kenya, United Nations Environment Programme, 2017, pp. 274-277).

[6] Mozersky, D. and Kammen, D. M. (2018). South Sudan's Renewable Energy Potential. United States Institute of Peace.

[7] Nagy, Z. and Szép, T. S. (2016). Losers of the Falling Oil Prices: Changes in Oil Vulnerability in the Oil Exporting Countries. International Journal of Energy Economics and Policy, 6 (4), 738-752.

[8] H. Plecher, H. (2018) "South Sudan: Inflation rate from 2012 to 2022 (compared to the previous year)," Statista, 10 February 2018. [Online]. Available: https:/www.statista.com/statistics/727347/inflation-rate-insouth-sudan/. [Accessed 14 May 2018].

[9] Roy Chowdhury, P. K., Weaver, J. E., Weber, E. M., Lunga, D., LeDoux, S. T. M., Rose, A. N. and Bhaduri, B. L. (2018). Electricity consumption patterns within cities: application of a data-driven settlement characterization method. International Journal of Digital Earth, 1-17.

[10] Resch, E., Bohne, R. A., Kvamsdal, T. and Lohne, J. (2016). Impact of urban density and building height on energy use in cities. Energy Procedia, 96, 800-814.

[11] Gargiulo, C., and Russo, L. (2017). Cities and energy consumption: a critical review. TeMA. Journal of Land Use,
Mobility and Environment, 10 (3), 259-278.

[12] World Bank. (2014). Doing Business: Understanding Regulations for Small and Medium-Size Enterprises. Washington, DC: World Bank Group. DOI: 10.1596/978-0-8213-9615-5. License: Creative Commons Attribution CC BY 3.0.

[13] SSNBS-(South Sudan National Bureau of Statistics) (2012). South Sudan Household Baseline survey report

[14] World Bank. (2013). South Sudan - Electricity sector strategy notes (ESSN) (English). Washington DC; World Bank. [Online]. Available: http://documents.worldbank.org/curated/en/354201468102894 108/South-Sudan-Electricity-sector-strategy-note-ESSN [Accessed 22 June 2018].

[15] UNDP/MoED (2013). The Republic of South Sudan, Sustainable Energy for All: Rapid Situation Assessment and Gap Analysis Report (draft). [Online]. Available: https://www.seforall.org/sites/default/files/South Sudan RAG A_EN_Released.pdf [Accessed 22 July 2018].

[16] Deng, J. M. (2009). Energy status in South Sudan. MSc. Thesis, University of Nairobi, Kenya

[17] Levy, B. S., and Patz, J. A. (2015). Climate change, human rights, and social justice. Annals of global health, 81 (3), 310322 .

[18] USAID (2016). Greenhouse Gas Emissions in South Sudan. [Online]. Available: https://www.climatelinks.org/sites/default/files/asset/document /2017_USAID_GHG\%20Emissions\%20Factsheet_South\%20 Sudan.pdf [Accessed 01 May 2018].

[19] AfDB (African Development bank) (2013). Juba Power Distribution System Rehabilitation and Expansion Project. [Online]. Available: https://www.afdb.org/en/news-andevents/adf-us-26-million-grant-to-expand-electricitydistribution-networks-in-south-sudan-12704/ [Accessed 19 May 2018].

[20] Foster, V., and Steinbuks, J. (2009). Paying the price for unreliable power supplies: In-house generation of electricity by firms in Africa. Policy Research Working Paper. Washington, DC: World Bank

[21] Thomas, T. T., Alexis, K. and Salomon, D. B. (2010). Electricity self-generation costs for industrial companies in Cameroon. Energies, 3 (7), 1353-1368.

[22] Ladu, J. L. C., Athiba, A. L., Lako, S. T. V. and Alfred, M. L. (2018). Investigation on the Impact of Water Pollution on Human Health in Juba County, Republic of South Sudan. Journal of Environment Pollution and Human Health, 6 (3), 89-95.

[23] Kadam, P., and Bhalerao, S. (2010). Sample size calculation. International journal of Ayurveda research, 1 (1), 55.

[24] Lindgren, G., Cox, D. R., Gudmundsson, G., Bondesson, L., Harsaae, E., Laake, P. and Lauritzen, S. L. (1981). Statistical analysis of time series: Some recent developments [with discussion and reply]. Scandinavian Journal of Statistics, 93115 .

[25] David, D. and Dodd, J. (2002). Qualitative research and the question of rigour. Qualitative Health Research, 12 (2), 279289. 
[26] Meng, X. (2013). Scalable simple random sampling and stratified sampling. In International Conference on Machine Learning (pp. 531-539).

[27] Kelle, U. (2006). Combining qualitative and quantitative methods in research practice: purposes and advantages. Qualitative research in psychology, 3 (4), 293-311.

[28] Niglas, K. (2000). Combining quantitative and qualitative approaches. In Paper presented at the European Conference on Educational Research (20), 23.

[29] Stewards, C. J. and Cash Jr, W. B. (2008). Interviewing: Principles and practices. $12^{\text {th }}$ Edition. New York: McGraw Hill.

[30] Rukmini; Nadjamuddin, H., Sak, T. A., and Ganding, S., (2014). Estimated Emissions from Diesel Generators of Containercranes at Makassar Container Terminal, International Journal of Mechanical and Production Engineering (IJMPE), 2 (11), 20-25.

[31] Goldthau, A. (2014). 'Rethinking the governance of energy infrastructure: Scale, decentralization and polycentrism,' Energy Research and Social Science 1 134-140.

[32] Anayochukwu, A. V., and Nnene, E. A. (2013). Measuring the environmental impact of power generation at GSM Base Station Sites. Electronic Journal of Energy and Environment, 1 (1), 71-79.

[33] Goldemberg J, Reddy AKN, Smith KR, Williams RH (2000) Rural energy in developing countries. In: World energy assessment. Goldemberg JO, ed. United Nations Development Programme, New York.

[34] Ericson, S. J., and Olis, D. R. (2019). A Comparison of Fuel Choice for Backup Generators (No. NREL/TP-6A50-72509). National Renewable Energy Lab. (NREL), Golden, CO (United States).

[35] US-EIA, (2014). "Saudi Arabia uses largest amount of crude oil for power generation since 2010," US Energy Information Administration, 24 September 2014. [Online]. Available: https://www.eia.gov/todayinenergy/detail.php?id=18111 [Accessed 17 July 2018].

[36] Ayik, A., Ijumba, N., Kabiri, C., and Goffin, P. (2018). Estimation of Solar Resource Potential in South Sudan Using Heliosat-4 Method. In 2018 IEEE PES Asia-Pacific Power and Energy Engineering Conference (APPEEC) (pp. 487492). IEEE.

[37] REEEP (2012). South Sudan. URL: https://www.reeep.org/south-sudan-2012

[38] Whiting, K. E., Amogpai, A., Carmona, L. G., and Esser, L. J. (2015). South Sudan: A Review of the Development of Sustainable Energy Policy and Practices. Investigación ambiental Cienciay política pública, 7 (1).

[39] Omar (2005). Biomass energy potential and future prospect in Sudan. Renewable and Sustainable Energy Reviews, 9, 1-27

[40] UNEP (2013). Municipal Solid Waste Composition Analysis Study Juba, South Sudan. [Online]. Available: $\mathrm{http}: / /$ postconflict.unep.ch/publications/UNEP South Sudan Juba_Waste_composition_2013.pdf. [Accessed 24 September 2018].
[41] Blinker, L and Grassi, S. (2001). Fact-finding mission to Sudan, 8-20 May 2001: for an investigation of Sudan's geothermal resources, the Jebel Marra area. UNESCO. [Online]. Available: http://unesdoc.unesco.org/images/0014/001418/141825eo.pdf [Accessed 26 May 2018].

[42] Steinbuks, J., and Foster, V. (2010). When do firms generate? Evidence on in-house electricity supply in Africa. Energy Economics, 32 (3), 505-514.

[43] Kranzberg, D. G. (2012). Submitted in Partial Fulfillment of the Requirements for the Degree of master's in engineering and Public Policy (Doctoral dissertation, McMaster University Hamilton).

[44] Ghosh, U. (2007). The role of black carbon in influencing availability of PAHs in sediments. Human and Ecological Risk Assessment, 13 (2), 276-285.

[45] Odubasa, A. (2017). Survey report for electricity generation and utilization in Juba (Unpublished).

[46] Mai, N. J. H., Mayai, A. T., and Tiitmamer, N. (2016). Sporadic Fuel Crisis in South Sudan: Causes Impacts and Solutions. The Sudd Institute.

[47] Hansen, U. E., Pedersen, M. B., and Nygaard, I. (2014). Review of Solar PV market development in East Africa. UNEP Risø Centre, Technical University of Denmark. (UNEP Risø Centre Working Paper Series; No. 12).

[48] Issa K., C. Natalie and C. Ann (2016). Solar Powered Transmission: A Case Study from South Sudan. [Online]. Available:

https://www.internews.org/sites/default/files/Solar Powered Transmission_CaseStudy_SouthSudan2016-11.pdf $\bar{f}$ [Accessed 02 April 2018].

[49] Marwa Hashem, M. (2017), November $14^{\text {th }}$. Jordan's Za'atari camp goes green with new solar plant. [Online]. Available: http://www.unhcr.org/en-

us/news/latest/2017/11/5a0ab9854/jordans-zaatari-camp\%20green-new-solar-plant.html [Accessed 19 July 2018].

[50] Cramton, P. (2017). Electricity market design. Oxford Review of Economic Policy, 33 (4), 589.

[51] Bublitz, A., Keles, D., Zimmermann, F., Fraunholz, C., and Fichtner, W. (2018). A survey on electricity market design: Insights from theory and real-world implementations of capacity remuneration mechanisms (No. 27). Working Paper Series in Production and Energy.

[52] Strbac, G., and Wolak, F. A. (2017). Electricity market design and renewables integration in developing countries; University of California: Berkeley, CA, USA.

[53] Beus, M., Pavić, I., Štritof, I., Capuder, T., and Pandžić, H. (2018). Electricity Market Design in Croatia within the European Electricity Market-Recommendations for Further Development. Energies, 11 (2), 346.

[54] Shen, D. and Yang, Q. (2012). Electricity Market Regulatory Reform and Competition - Case Study of the New Zealand Electricity Market in: Wu, Y., Shi, X., Kimura, F. (eds.), Energy Market Integration in East Asia: Theories, Electricity Sector and Subsidies, ERIA Research Project Report 2011-17, Jakarta: ERIA, 103-139. 